Dijk, G.M. van, Veenhof, C., Spreeuwenberg, P., Coene, N., Burger, B.J., Schaardenburg, D.J. van, Ende, C.H.M. van den, Lankhorst, G.J., Dekker, J. Prognosis of limitations in activities in osteoarthritis of the hip or knee: a

\begin{tabular}{|l|l|}
\hline Postprint Version & 1.0 \\
\hline Journal website & $\underline{\text { http://www.archives-pmr.org/article/S0003-9993(09)00755-2/abstract }}$ \\
\hline Pubmed link & $\underline{\text { http://www.ncbi.nlm.nih.gov/pubmed/20103397 }}$ \\
\hline DOI & $10.1016 /$ j.apmr.2009.08.147 \\
\hline
\end{tabular}

This is a NIVEL certified Post Print, more info at http://www.nivel.eu

\title{
Prognosis of Limitations in Activities in Osteoarthritis of the Hip or Knee: A 3-Year Cohort Study
}

\author{
Gabriella M. VAn Dijk, PT, PhD, Cindy Veenhof, PT, PhD, Peter Spreeuwenberg, MA,

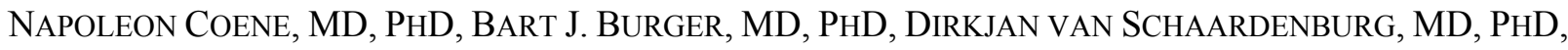 \\ Cornelia H. van Den Ende, PT, PhD, GuUs J. LankHorst, PhD, JoOst DeKKer, PhD,
} ON BEHALF OF THE CARPA STUDY GROUP

From the Netherlands Institute for Health Services Research, Utrecht (van Dijk, Veenhof, Spreeuwenberg); HAGA Ziekenhuis, Department of Ortopeadics, The Hague (Coene); Medisch Centrum Alkmaar, Department of Rehabilitation, Alkmaar (Burger); Jan van Breemen Institute, Amsterdam (Schaardenburg); Department of Rheumatology, Sint Maartenskliniek, Nijmegen (van den Ende); and Department of Rehabilitation Medicine, EMGO Institute, VU University Medical Centre, Amsterdam (Lankhorst, Dekker), The Netherlands. Supported by the Netherlands Organization for Health Research and Development (ZON-MW Revalidatieonderzoek). No commercial party having a direct financial interest in the results of the research supporting this article has or will confer a benefit on the authors or on any organization with which the authors are associated. Reprint requests to Gabriella M. van Dijk, PT, PhD, Mozartlaan 131, 2215JW Voorhout, The Netherlands, e-mail: info@gabriellamvandijk.com.

\begin{abstract}
.
Objective: To describe the course of limitations in activities in elderly patients with osteoarthritis (OA) of the hip or knee over a follow-up period of 3 years, and to identify prognostic factors of the course of limitations in activities, focusing on body functions, comorbidity, and cognitive functioning.

Design: A longitudinal cohort study with 3 years of followup.

Measurements were conducted annually. Statistical analyses included t tests, univariate regression analyses, and multivariate regression analyses.

Setting: Rehabilitation centers and hospitals (Departments of Orthopedics, Rheumatology, and Rehabilitation) in The Netherlands.

Participants: Patients ( $=237)$ with hip or knee OA.

Interventions: Not applicable.

Main Outcome Measures: Patient-perceived change, selfreported limitations in activities measured by the Western Ontario and McMaster Universities Osteoarthritis Index (WOMAC), and observed limitations in activities (timed walking test). Prognostic factors: demographic data, clinical data, body function (pain, muscle strength, range of motion [ROM]), comorbidity, and cognitive functioning (cognitive decline, memory, attention).
\end{abstract}


Dijk, G.M. van, Veenhof, C., Spreeuwenberg, P., Coene, N., Burger, B.J., Schaardenburg, D.J. van, Ende, C.H.M. van den, Lankhorst, G.J., Dekker, J. Prognosis of limitations in activities in osteoarthritis of the hip or knee: a 3-year cohort study. Archives of Physical Medicine and Rehabilitation: 2010, 91(1), 58-66

Results: Self-reported limitations in activities measured by the WOMAC improved slightly after 3-year follow-up. In knee OA, reduced ROM at 1-year follow-up ( $\beta=.120)$, increased pain at 1-year follow-up ( $\beta=-.177)$, and higher morbidity count $(\beta=-.180)$ predicted worsening of self-reported limitations in activities. In hip OA, reduced ROM at 1-year followup ( $\beta=.201$ for hip external rotation and $\beta=.144$ for knee extension), increased pain at 1 -year follow-up ( $\beta=-.134)$, higher morbidity count $(\beta=-.220)$, or the presence of moderate to severe cardiac disease $(\beta=-.214)$ and poorer cognitive functioning $(\beta=.181)$ predicted worsening of self-reported limitations in activities. Performance-based limitations in activities measured by the timed walking test did not change after 3 years of follow-up. In knee OA, decreased muscle strength at 1-year follow-up $(\beta=-.272)$ and higher morbidity count ( $\beta$ $=.199$ ) predicted worsening of performance-based limitations in activities.

In hip OA, better ROM ( $\beta=.182)$, higher morbidity count $(\beta=.232)$, or the presence of moderate to severe cardiac and eye-ear-nose-throat disease $(\beta=.210$ and $\beta=.188$, respectively) and older age ( $\beta=.355$ ) predicted worsening of performance- based limitations in activities.

Conclusions: Overall, at the group level, limitations in activities of patients with OA of the hip or knee recruited from hospitals and rehabilitation centers seem fairly stable during the first 3 years of follow-up. However, at the level of individual patients, considerable variation occurs. Prognostic factors for worsening of limitations in activities include increased pain, reduced ROM, and decreased muscle strength at 1-year follow-up; higher morbidity count; and to a lesser extent poor cognitive functioning.

Through the years, research has focused increasingly on aspects of rehabilitation in elderly patients. Successful aging and achieving optimal functioning and fulfillment are key aspects in older age and in rehabilitation. Demographic developments will lead to an increasing number of elderly people, making rehabilitation of elderly patients an important aspect of health care and research.1 Elderly patients with OA of the hip or knee often experience physical impairments, pain, and limitations in activities.2-6 Knowledge about the course of limitations in activities and prognostic factors is important for optimizing rehabilitation for patients with OA of the hip or the knee. Previous studies in OA of the hip or knee showed that after 3 or more years of follow-up, worsening of limitations in activities becomes evident. 7 The association between prognostic factors and limitations in activities in OA has been studied frequently in cross-sectional studies.4-6,8-12 However, factors found in crosssectional studies to be associated with limitations in activities may or may not predict the course of limitations in activities.

Longitudinal studies on prognostic factors in OA found limited evidence for pain, BMI, age, muscle strength, comorbidity, mental health, and social support as prognostic factors for the course of limitations in activities.7,13-16 It is hypothesized that the process of rehabilitation in elderly patients with OA and their level of functioning are affected by factors related to aging. In the elderly, the gradual development of physical impairments, comorbidity, and cognitive impairments is common. With increasing age, decreased muscle strength and reduced joint ROM are expected. Studies show that these factors are associated with increased limitations in activities in patients with OA of the hip or knee.4-7,9 Furthermore, the prevalence of chronic conditions increases with age: most of the elderly have at least one chronic disease.17 Patients with OA have a significantly higher risk of developing comorbidity than do non-OA patients. 18 There is some evidence that comorbidity is related to functioning in OA.19 Likewise, it is expected that elderly people experience more cognitive impairments, which in turn may influence the course of limitations in activities in elderly patients with OA. Although these factors have been studied separately, it is not known whether comorbidity and cognitive functioning contribute to the course of limitations in activities, in addition to the effects of body functions (muscle strength, joint ROM, and pain). 
Dijk, G.M. van, Veenhof, C., Spreeuwenberg, P., Coene, N., Burger, B.J., Schaardenburg, D.J. van, Ende, C.H.M. van den, Lankhorst, G.J., Dekker, J. Prognosis of limitations in activities in osteoarthritis of the hip or knee: a 3-year cohort study. Archives of Physical Medicine and Rehabilitation: 2010, 91(1), 58-66

The objectives of this study were (1) to describe the course of limitations in activities in elderly patients with OA of the hip or knee over a follow-up period of 3 years, and (2) to identify prognostic factors of the course of limitations in activities, focusing on body functions, comorbidity, and cognitive functioning.

\section{[LIST 1]}

\section{METHODS}

\section{Design}

A longitudinal study with a follow-up period of 3 years was conducted in 237 patients with knee or hip OA. Measurements were performed annually and were carried out by means of tests, questionnaires, and interviews. The study was approved by the Medical Ethics Committee of the VU University Medical Centre, Amsterdam, The Netherlands.

\section{Study Population}

Patients were recruited from 3 rehabilitation centers and 2 hospitals (Departments of Orthopedics, Rheumatology, or Rehabilitation). Inclusion criteria were (1) diagnosis of hip or knee OA by a medical specialist according to radiologic criteria or clinical criteria of the American College of Rheumatology20,21; (2) age between 50 and 84 years; (3) referral to a hospital or rehabilitation center less than 1 year before inclusion; (4) at least moderate functional problems (Lequesne Algofunctional Index score 35 )22; and (5) informed consent.

Exclusion criteria were (1) insufficient understanding of the Dutch language, and (2) expected death within 1 year after inclusion, due to terminal illness.

\section{Measurements}

All assessments were conducted at the same time and were performed at test locations by the researcher or the research assistant.

\section{Demographic and clinical data.}

Demographic and clinical data were collected on age, sex, height, weight, location of OA, duration of complaints, other joint complaints (patients were asked whether they had other joint complaints of the neck, shoulders, hands, back, feet, or other joints, apart from their hip or knee OA), radiologic impairments, level of education, and marital status. BMI was calculated; obesity was defined as a BMI higher than $30 \mathrm{~kg} / \mathrm{m} 2$. If available, radiographs of the hip and knee that were recorded in the year before inclusion were scored on joint space width and osteophytes, following a standardized procedure.23 From these scores, Kellgren and Lawrence grades were calculated.

\section{Limitations in activities.}

Self-reported limitations in activities were measured using the physical functioning subscale of the WOMAC.24,25 A higher score on the standardized WOMAC (range, 0-100) reflects fewer limitations. Performance- based limitations in activities were measured using a $10-\mathrm{m}$ timed walking test. 26 If necessary, patients could use an assistive device during the timed walking test. Use of devices was recorded, and consequently devices were also used during the assessments after 1, 2, and 3 years. A higher score on the timed walking test reflects more limitations. Also, patients were asked to record whether their complaints of hip or knee OA had changed after 3 years of follow-up on a scale from 1 to 8 (patientperceived change), varying from 1 (no complaints) to 8 (major worsening). Scores were recoded to improvement (scores, 1-3), no change (scores, 4-6), and worsening (scores, 7 or 8).

\section{Body functions.}

Assisted active ROM was measured in both legs using goniometry, following a standardized protocol. 27 For the hip, internal rotation, external rotation, and flexion were measured. For the knee, flexion and extension were measured. Isometric muscle strength of knee extension and hip abduction was measured in both legs with a handheld dynamometer, the MicroFet,a using a break test. Patients were asked to deliver maximum strength against the researcher's resistance. A standardized protocol describing postures, instructions, and procedure was used.28 The measurements of both ROM and muscle strength were 
repeated twice. The average score was used in the analyses. Patients rated their pain on a VAS, before the physical assessment. A higher score on the VAS reflects more pain.

\section{Comorbidity.}

Information about comorbidity was gathered in an interview with the patients by using the CIRS.29-31 The CIRS consists of 13 body systems. Scoring is weighted by the severity of the comorbid condition. Severity scores range from 0 (none) to 4 (extremely severe) (appendix 1). Because all patients had OA (OA can be regarded as the index disease), they all scored positive on CIRS 10 and for this reason, diseases in CIRS 10 (muscle, bone, and skin diseases) were not used in the analyses. The indices of comorbidity derived from the CIRS are the presence of the various disease categories (moderate to severe comorbidity, CIRS $\beta 2$ ) and the morbidity count (the number of diseases on which the patients scored a severity of $\beta 2$ ).

\section{Cognitive functioning.}

Various aspects of cognitive functioning were measured. First, the 20 -item cognitive screening test was applied. This test was developed as a screening instrument for cognitive decline in the elderly.32 Scores range from 0 to 20 . An indication of cognitive decline was calculated.

For patients older than 81 years, cognitive decline is defined by a score on the 20 -item cognitive screening test of 10 or less; for patients 81 years or younger, cognitive decline is defined by a score of 12 or less. Second, a memory test, extracted from the Wechsler Adult Intelligence Scale, was applied.33,34 Patients were asked to recall series of numbers, both backward and forward. The score was calculated by the number of correctly repeated items. Backward and forward scores range from 0 to 21 . Finally, to assess visual selective attention, the abridged Stroop Color-Word Test was applied.35,36 The variables derived from the Stroop test are the number of uncorrected mistakes in part III of the test and the interference score (the time needed for part III minus the time needed for part II).

\section{[FIGURE 1] [TABLE 1]}

\section{Statistical Analyses}

Following the method used by Steultjens et al,4,5 indices for ROM (hip flexion, hip external rotation, hip internal rotation, knee extension and knee flexion) and muscle strength (hip abduction and knee extension) were calculated using the sum score for left and right for each movement. Before this calculation, scores for muscle strength on the MicroFet were divided by body weight.

For radiologic impairments, a combined score for the hip and a combined score for the knee were calculated. For the multivariate regression analyses, radiologic impairments of the knee and radiologic impairments of the hip were calculated as positive if patients showed severe joint space narrowing or severe osteophytes in either the hip or the knee (rating $=3$ ).

Any severe abnormality resulted in a positive score on these variables.

All analyses were conducted for knee OA and hip OA separately. To describe the course of limitations in activities, 2 analyses were performed: (1) multilevel analyses and (2) paired samples $t$ tests in SPSS (version 11.5). ${ }^{\mathrm{b}}$ Because both methods revealed similar results, it was decided to present the results from the SPSS analyses. Means for scores on the WOMAC and the timed walking test were calculated for all measurements.

Means after 1 year (t1), after 2 years (t2), and after 3 years ( $\mathrm{t} 3$ ) were compared with the mean at baseline (t0) and were tested by a paired samples $t$ test.

\section{[TABLE 2] [TABLE 3]}

To determine which factors influence the course of limitations in activities, regression analyses were performed. For all possible prognostic factors, univariate regression analyses were conducted, with the WOMAC physical functioning score at $\mathrm{t} 3$ and the timed walking test at $\mathrm{t} 3$ as dependent variables. To correct for baseline score on both outcome measures, scores at t0 were entered as the first variable in all analyses. Furthermore, stepwise multiple regression analyses were performed, again using the WOMAC physical functioning score and timed walking test as dependent variables. Variables were added to the model if the $P$ value was less than .05 . The following blocks of variables, numbered (1) to (6), were entered 
stepwise: (1) radiologic impairments; (2) ROM and muscle strength: ROM (hip flexion, hip flexion: change from $\mathrm{t} 0-\mathrm{t} 1$; hip internal rotation, hip internal rotation: change from $\mathrm{t} 0-\mathrm{t} 1$; hip external rotation, hip external rotation: change from $\mathrm{t} 0-\mathrm{t} 1$; knee flexion, knee flexion: change from $\mathrm{t} 0-\mathrm{t} 1$; knee extension, knee extension: change from $\mathrm{t} 0-\mathrm{t} 1$ ), muscle strength (knee extension, knee extension: change from $\mathrm{t} 0-\mathrm{t} 1$; hip abduction, hip abduction: change from $\mathrm{t} 0-\mathrm{t} 1$ ); (3) pain (pain measured by the VAS, pain: change from $\mathrm{t} 0$ t1); (4) comorbidity (morbidity count [CIRS $\beta 2$ ], presence of CIRS 1-9, CIRS 11-13); (5) cognitive functioning (20-item cognitive screening test, numbers forward, numbers backward, Stroop interference score, Stroop uncorrected mistakes); and (6) other factors (age, sex, use of devices, use of medication, surgery before inclusion, surgery during follow-up, BMI, obesity $\left.\left[\mathrm{BMI}=30 \mathrm{~kg} / \mathrm{m}^{2}\right]\right)$. Because it is known that body functions have an effect on disability,4-7,9 these variables were entered first into the regression analyses.

Subsequently, comorbidity, cognitive functioning, and other factors were entered to determine whether these variables contributed in addition to the variables entered previously. Factors with a $P$ value greater than 0.2 were excluded from the model.

SPSS was used for all statistical analyses.

\section{RESULTS}

\section{Study Population}

Baseline characteristics of the study population are presented in table 1 . The majority of the patients (79\%) originated from Departments of Orthopedics. The other $21 \%$ came from Departments of Rheumatology and Departments of Rehabilitation.

On average, patients had had hip and knee complaints for 9.5 years. Only $13 \%$ had no other joint complaints apart from knee or hip problems. Frequently occurring other joint complaints were hand and back problems.

Initially, 775 patients with OA of the hip or knee who visited the department in the year before inclusion were contacted by mail and were asked to participate in the study. Of those patients who volunteered (n $=364), 288$ were included and 76 were excluded. Reasons for exclusion were age $(n=2)$, language $(n=4)$, less than moderate functional problems $(\mathrm{n}=48)$, and referral longer than 1 year before inclusion $(\mathrm{n}=22)$. No differences were found between the group of patients that was initially contacted $(n=775)$ and the patients who were included in the study $(\mathrm{n}=288)$ with regard to age and sex. Compared with our study population, patients who were initially contacted had both hip and knee OA less frequently (6.2\% vs $26.5 \%)$, and more frequently had either knee OA $(59.5 \%$ vs $48.4 \%)$ or hip OA (34.3\% vs $25.1 \%)$. Of the 288 patients who were included in the study, 237 patients $(82 \%)$ also participated after 3 years. Baseline characteristics of completers were compared with noncompleters. According to the baseline measurement, patients who completed the study had a higher level of education ( $21.6 \%$ vs $17.6 \%$ higher education and $15.7 \%$ vs $25.5 \%$ lower education), fewer limitations (WOMAC score, 63.1 vs 51.3; timed walking test score, $10.0 \mathrm{~s}$ vs $11.9 \mathrm{~s}$ ), a lower morbidity count (median, 2.0 vs 4.0 ), greater muscle strength (hip abduction, 9.1 vs 7.8 ; knee extension, 7.9 vs 7.0), and reported less pain (VAS, 4.6 vs 5.6). No differences were found for age, sex, duration of complaints, BMI, marital status, ROM, and cognitive functioning. Of the 237 patients who were included in the longitudinal study, 187 patients (79\%) performed the timed walking test after 3 years. No differences were found between patients who were lost to follow-up with regard to the timed walking test and patients who participated, apart from the WOMAC score (57.3 vs 66.2 , respectively) and age (68.8y vs $64.6 \mathrm{y}$, respectively). A flowchart of exclusion and loss to follow-up is presented in figure 1 .

\section{[TABLE 4]}

\section{Course of Complaints and Limitations in Activities}

After 3 years of follow-up $50 \%$ of the patients with knee OA $(n=174)$ reported that their complaints had remained unchanged.

Worsening was reported by $26 \%$ of the patients, and improvement by $24 \%$. Of the patients with hip OA (n $\beta 123), 53.3 \%$ reported that their complaints had remained unchanged after 3 years of follow-up. A worsening was reported by $24.6 \%$ of the patients, and $21.9 \%$ reported that their complaints had improved. 
Dijk, G.M. van, Veenhof, C., Spreeuwenberg, P., Coene, N., Burger, B.J., Schaardenburg, D.J. van, Ende, C.H.M. van den, Lankhorst, G.J., Dekker, J. Prognosis of limitations in activities in osteoarthritis of the hip or knee: a 3-year cohort study. Archives of Physical Medicine and Rehabilitation: 2010, 91(1), 58-66

Table 2 presents the results for the course of self-reported and performance-based limitations in activities. The results show that self-reported limitations in activities measured by the WOMAC improved slightly and significantly after 3 years of follow-up. Performance-based limitations in activities, on the other hand, did not change over 3 years. The results for hip and knee OA were similar. As indicated by the SDs of the change scores, there were considerable within-patient differences: some patients improved, while others deteriorated.

\section{Prognostic Factors of Functional Course: Self-Reported Limitations in Activities}

In table 3, univariate regression coefficients are presented for significant prognostic factors and the course of self-reported limitations in activities measured by the WOMAC.

Factors with significant univariate correlations were entered into the multivariate regression analyses. The results of these analyses are presented in table 4 . In knee OA, the results show that reduced ROM hip external rotation at 1 -year follow-up ( $\beta=.120)$, increased pain at 1 -year follow-up ( $\beta=-.177)$, and a higher morbidity count $(\beta=-.180)$ were associated with worsening of self-reported limitations in activities.

For hip OA, additional prognostic factors were identified. As was the case for knee OA, reduced ROM hip external rotation at 1 -year follow-up ( $\beta=.201$ ), increased pain at 1-year follow-up ( $\beta=-.134)$, and higher morbidity count $(\beta=-.220)$ were found to be associated with worsening of self-reported limitations in activities. Furthermore, reduced ROM knee extension at 1-year follow-up ( $\beta=.144)$ and poorer cognitive functioning ( $\beta=.181$ ) were associated with worsening of self-reported limitations in activities. If the presence of specific disease categories was entered instead of overall morbidity count, the presence of moderate to severe cardiac disease was associated $(\beta=-.214)$ with worsening of self-reported limitations in activities, apart from the previously mentioned variables (results are not shown).

\section{Prognostic Factors of Functional Course: Performance-Based Limitations in Activities}

In table 5, univariate regression coefficients are presented for significant prognostic factors and the course of performance-based limitations in activities measured by the timed walking test.

Factors with significant univariate correlations were entered into the multivariate regression analyses. The results of these analyses are presented in table 6 . For knee OA, decreased muscle strength hip abduction at 1-year follow-up ( $\beta=-.272)$ and higher morbidity count $(\beta=.199)$ were associated with worsening of performance-based limitations in activities.

For hip OA, higher ROM hip flexion at baseline ( $\beta=.182$ ), higher morbidity count ( $\beta=.232$ ), and older age $(\beta=.355)$ were found to be associated with worsening of performance-based limitations in activities. In this model, $45 \%$ of the variance was explained. If the presence of specific disease categories was entered instead of overall morbidity count, the presence of moderate to severe cardiac disease and eye-ear-nosethroat disease was associated ( $\beta=.210$ and $\beta=.188$, respectively) with worsening of performance-based limitations in activities, apart from the previously mentioned variables (results are not shown).

[table 5]

\section{DISCUSSION}

The objective of the study was to describe the course of limitations in activities in elderly patients with OA of the hip or knee and to identify prognostic factors, focusing on body functions, comorbidity, and cognitive functioning.

In hip OA and knee OA, self-reported limitations in activities improved after 3 years of follow-up. This improvement, however, was not clinically relevant: overall improvement was $4 \%$, far less than the minimum clinically important change, as reported in the literature. Angst et al37 concluded that in patients with OA, changes over $12 \%$ compared with baseline are clinically relevant, while Tubach et al 38 stated that for physical function on the WOMAC, the minimum clinically important change is between $21 \%$ and $26 \%$. Performance-based limitations in activities remained unchanged.

In contrast to the stability at group level, individual patients showed considerable differences: some patients improved, while others deteriorated. Thus, at the group level, limitations in activities of patients with OA of the hip or knee are fairly stable during the first 3 years of follow-up. At the level of individual patients, considerable variation occurs in the course of limitations in activities.

Identification of prognostic factors is therefore highly relevant. 
Dijk, G.M. van, Veenhof, C., Spreeuwenberg, P., Coene, N., Burger, B.J., Schaardenburg, D.J. van, Ende, C.H.M. van den, Lankhorst, G.J., Dekker, J. Prognosis of limitations in activities in osteoarthritis of the hip or knee: a 3-year cohort study. Archives of Physical Medicine and Rehabilitation: 2010, 91(1), 58-66

Several prognostic factors for worsening of self-reported and performance-based limitations in activities were identified and are schematically summarized in tables 7 and 8.

\section{[TABLE 7] [TABLE 6]}

Previous research on body functions has been mainly directed towards the influence of decreased muscle strength on limitations in activities.7,16,17,39 Studies on the association between ROM and limitations in activities are scarce. 5 The present study is the first longitudinal study reporting on reduced ROM at 1-year follow-up as a prognostic risk factor for worsening of limitations in activities after 3 years. The association between better ROM hip flexion and performance-based limitations in activities in hip OA is difficult to explain; we believe this is a chance finding.

The association of pain with self-reported limitations has been described in previous studies.14,16,40 Experiencing pain restrains patients with hip or knee OA from performing certain activities. In addition, pain might lead to fear of pain during activities, which in turn results in avoidance of these activities.

Comorbidity has been described in previous studies as a risk factor for worsening of limitations in activities.18,19,31,41 The present study is the first to analyze the role of comorbidity in detail. In hip OA, we found that both a higher morbidity count and the presence of moderate to severe cardiac disease and eye-ear-nose-throat disease predicted worsening of limitations in activities. In knee OA, a higher morbidity count predicted worsening of limitations in activities. Elderly patients frequently have OA, cardiac disease, or eye-ear-nose-throat disease (especially problems with vision), resulting in limitations in activities. The combination of OA and cardiac disease, as well as the combination of OA and eye-ear-nose-throat disease (specifically vision problems), was found to be associated with additional limitations in activities in earlier research.42 Thus, cardiac diseases and eye-ear-nose-throat diseases are highly relevant comorbidities in the rehabilitation of OA patients.

Although its influence is smaller than the above-mentioned factors, cognitive functioning is a relevant risk factor for worsening of limitations in activities as well. The relatively small influence might partly be explained by the fact that cognitive decline was not found in the patients included in our study. All had normal cognitive functioning, scoring above the cutoff scores described in the Methods section.

\section{Study Limitations}

Some methodological issues and limitations of the study must be considered. First, patients were recruited from hospitals and rehabilitation centers. They received treatment as usual, such as medication, surgery, and physiotherapy. Furthermore, because all patients were recruited from hospitals or rehabilitation centers, they were likely to have serious complaints due to their OA and to have at least moderate functional problems at inclusion. It is possible that the slight improvement of limitations in activities found in this study should be attributed to receiving treatment (confounding) or to the state of exacerbation - having complaints and functional problems of the patients at inclusion (regression to the mean). Therefore, the results of the present study cannot be generalized to the general population that has OA. Nevertheless, the findings are applicable to the group of OA patients attending hospitals and rehabilitation centers; this is a highly relevant group. Second, patients in this study were followed up for 3 years, and little or no (clinically relevant) change of limitations in activities was found. Because previous studies showed worsening after more than 3 years of follow-up, further research with a follow-up of more than 3 years might reveal interesting findings. In the present research program, measurements are performed up to 5 years, and results on this longer follow-up will be presented in future reports. Third, $18 \%$ of patients included at baseline did not complete the 3 years of follow-up. We found that patients who completed the study had fewer problems than those who were lost to follow-up. Secondary analyses on change in selfreported limitations in activities from baseline to 1-year follow- up showed no differences between completers and those lost to follow-up (data not shown). We therefore assume that the course of self-reported limitations in activities over 3 years presented in this study is applicable to the total group of 288 patients who were originally included in the study. For performance- based limitations on the other hand, secondary analyses showed that in patients who were lost to follow-up at 3 years, worsening was already seen at 1-year follow-up, while patients who completed the study showed no change at 1-year follow- up (data not shown). The present study may therefore underestimate the decrease in performance-based limitations in activities. Fourth, patients who dropped out of the study often commented that the tests were demanding. So although 
Dijk, G.M. van, Veenhof, C., Spreeuwenberg, P., Coene, N., Burger, B.J., Schaardenburg, D.J. van, Ende, C.H.M. van den, Lankhorst, G.J., Dekker, J. Prognosis of limitations in activities in osteoarthritis of the hip or knee: a 3-year cohort study. Archives of Physical Medicine and Rehabilitation: 2010, 91(1), 58-66

studies on elderly patients are highly relevant, the physical demands of performing tests and answering questionnaires constitute a major challenge for research among the elderly.

Studies on prognostic factors are highly relevant for clinical practice. This relevance is 2 -fold. First, prognostic factors can be used to inform patients about their expected future limitations in activities. The present results point to pain, reduced ROM, reduced muscle strength, comorbidity, and to a lesser extent relatively poor cognitive functioning as predictors of worsening of limitations in activities. Second, prognostic factors can be used to set optimal rehabilitation goals. Rehabilitation might also target pain, reduced ROM, reduced muscle strength, comorbidity, and to a lesser extent relatively poor cognitive functioning. Of course, intervention studies are required to substantiate claims regarding the effects of changing these prognostic factors.

\section{[TABLE 8]}

\section{[APPENDIX 1]}

\section{CONCLUSIONS}

Overall, it can be concluded that at the group level, limitations in activities of patients with OA of the hip or knee recruited from hospitals and rehabilitation centers seem fairly stable during the first 3 years of follow-up.

However, at the level of individual patients, considerable variation occurs. Prognostic factors for worsening of limitations in activities include increased pain, reduced ROM, and decreased muscle strength at 1 year follow-up; higher morbidity count; and to a lesser extent relatively poor cognitive functioning.

ACKNOWLEDGMENTS: Participants in the CARPA Study Group are Gabriella M. van Dijk, PhD, Cindy Veenhof, PhD, Bart Post, PhD, Hans Speelman, PhD, Rob J. de Haan, PhD, Janneke Stolwijk-Swüste, PhD, Anita Beelen, PhD, Frans Nollet, PhD, Martijn P.M. Steltjens, PhD, Joost Dekker, PhD, Guustaaf J. Lankhorst, PhD.

\section{REFERENCES}

1. ZonMv. 2008. Available at: http://www.zonmw.nl/nl/programma-s/ alle-programma-s/succesvol-ouderworden/. Accessed September 24, 2009.

2. Guccione AA, Felson DT, Anderson JJ. Defining arthritis and measuring functional status in elders: methodological issues in the study of disease and physical disability. Am J Public Health 1990;80:945-9.

3. McAlindon TE, Cooper C, Kirwan JR, Dieppe PA. Determinants of disability in osteoarthritis of the knee. Ann Rheum Dis 1993; 52:258-62.

4. Steultjens M, Dekker J, van Baar ME, Oostendorp RA, Bijlsma JW. Muscle strength, pain and disability in patients with osteoarthritis.

Clin Rehabil 2001;15:331-41.

5. Steultjens M, Dekker J, van Baar M, Oostendorp R, Bijlsma J.

Range of joint motion and disability in patients with osteoarthritis of the knee or hip. Rheumatology 2000;39:955-61.

6. van Baar ME, Dekker J, Lemmens JA, Oostendorp RA, Bijlsma JW. Pain and disability in patients with osteoarthritis of hip or knee: the relationship with articular, kinesiological and psychological characteristics. J Rheumatol 1998;25:125-33.

7. van Dijk GM, Dekker J, Veenhof C, van den Ende $\mathrm{CH}$. Course of functional status and pain in osteoarthritis of the hip and knee: a systematic review. Arthritis Care Res 2006;55:779-85.

8. Creamer $\mathrm{P}$, Lethbridge-Cejku M, Hochberg MC. Factors associated with functional impairment in symptomatic knee OA. Rheumatology 2000;39:490-6.

9. Dekker J, Boot B, van der Woude L, Bijlsma JW. Pain and disability in osteoarthritis: a review of behavioral mechanisms. J Behav Med 1992;15:189-214.

10. Kee CC. Older adults with osteoarthritis: psychological status and physical function. J Gerontol Nurs 2003;29:26-31. 
Dijk, G.M. van, Veenhof, C., Spreeuwenberg, P., Coene, N., Burger, B.J., Schaardenburg, D.J. van, Ende, C.H.M. van den, Lankhorst, G.J., Dekker, J. Prognosis of limitations in activities in osteoarthritis of the hip or knee: a 3-year cohort study. Archives of Physical Medicine and Rehabilitation: 2010, 91(1), 58-66

11. Salaffi F, Cavalieri F, Nolli M, Ferraccioli G. Analysis of disability in knee OA: relationship with age and psychological variables but not with radiographic score. J Rheumatol 1991; 18:1581-6.

12. van Dijk GM, Veenhof C, Lankhorsti G, Dekker J. Limitations in activities in patients with osteoarthritis of the hip or knee: the relationship with body functions, comorbidity and cognitive functioning.

Disabil Rehabil 2009;31:1685-95.

13. Mallen CD, Peat G, Thomas E, Lacey R, Croft P. Predicting poor functional outcome in communitydwelling older adults with knee pain: prognostic value of generic indicators. Ann Rheum Dis 2007;66:1456-61.

14. Paradowski PT, Englund M, Lohmander LS, Roos EM. The effect of patient characteristics on variability in pain and function over two years in early knee osteoarthritis. Health Qual Life Outcomes 2005;3:59.

15. Peters TJ, Sanders C, Dieppe P, Donovan J. Factors associated with change in pain and disability over time: a community-based prospective observational study of hip and knee osteoarthritis. Br J Gen Pract 2005;55:205-11.

16. Weigl M, Angst F, Aeschlimann A, Lehmann S, Stucki G. Predictors for response to rehabilitation in patients with hip or knee osteoarthritis: a comparison of logistic regression models with three different definitions of responder. Osteoarthritis Cartilage 2006;14:641-51.

17. Schellevis FG, van der Velden J, van de Lisdonk E, van Eijk JT, van Weel C. Comorbidity of chronic diseases in general practice.

J Clin Epidemiol 1993;46:469-73.

18. Gabriel SE, Crowson CS, O'Fallon WM. A comparison of two comorbidity instruments in arthritis. J Clin Epidemiol 1999;52: 1137-42.

19. Marks R, Allegrante JP. Comorbid disease profiles of adults with end-stage hip osteoarthritis. Med Sci Monit 2002;8:CR305-9.

20. Altman R, Asch E, Bloch D, et al. Development of criteria for the classification and reporting of osteoarthritis. Classification of osteoarthritis of the knee. Arthritis Rheum 1986;29:1039-49.

21. Altman R, Alarcon G, Appelrouth D, et al. The American College of Rheumatology criteria for the classification and reporting of osteoarthritis of the hip. Arthritis Rheum 1991;34:505-14.

22. Lequesne M, Mery C, Samson M, Gerard D. Indices of severity for osteoarthritis of the hip and knee. Scand J Rheumatol 1987; 18(Suppl 65):85-9.

23. Altman R, Hochberg M, Murphy W, Wolfe F, Lequesne M. Atlas of individual radiographic features in osteoarthritis. Osteoarthritis Cartilage 1995;3(Suppl A):3-70.

24. Bellamy N, Buchanan W, Goldsmith C, Campbell J, Stitt L.

Validation study of WOMAC: a health status instrument for measuring clinically-important patient-relevant outcomes following total hip or knee arthroplasty in osteoarthritis. J Orthop Rheumatol 1988;1:95-108.

25. Roorda LD, Jones CA, Waltz M, et al. Satisfactory cross cultural equivalence of the Dutch WOMAC in patients with hip osteoarthritis waiting for arthroplasty. Ann Rheum Dis 2004;63:36-42.

26. Wade D, Wood V, Heller A, Maggs J, Hewer R. Walking after stroke. Scand J Rehabil Med 1987;19:2530.

27. Norkin C, White D. Measurement of joint motion: a guide to goniometry. Philadelphia: FA Davis; 1986.

28. Bohannon R. Muscle strength testing with hand-held dynamometers.

In: Amundsen L, editor. Muscle strength testing: instrumented and non-instrumented systems. New York: Churchill Livingstone; 1990. p 69-88.

29. Conwell Y, Forbes N, Cox C, Caine E. Validation of a measure of physical illness burden at autopsy: the Cumulative Illness Rating Scale. J Am Geriatr Soc 1993;41:38-41.

30. Linn BS, Linn MW, Gurel L. Cumulative Illness Rating Scale.

J Am Geriatr Soc 1968;16:622-5.

31. van Dijk GM, Veenhof C, Schellevis FG, et al. Comorbidity, limitations in activities and pain in patients with osteoarthritis of hip or knee. BMC Musculoskelet Disord 2008;9:95.

32. De Graaf A, Deelman B, Fens J. Cognitieve Screeningstest (CST).

In: Bouma A, Mulder J, Lindenboom J, editors. Neuropsychologische diagnostiek; handboek. 1996; Lisse: Swets \& Zeitlinger. p I11-5.

33. Lindenboom J, Matto D. Cijferreeksen en Knox blokken als concentratietests voor ouderen. Tijdschr Gerontol Geriatr 1994; 25:63-8.

34. Wechsler D, Stinissen J, Willems P, Coetsier P, Hulsman W.

Wechsler Adult Intelligence Scale. In: Bouma A, Mulder J, Lindenboom J, editors. Neuropsychologische diagnostiek: handboek.

1996; Lisse: Swets \& Zeitlinger. p A1-28.

35. Klein M, Ponds R, Houx P, Jolles J. Effects of test duration on age-related difference in Stroop interference. J Clin Exp Neuropsychol 1997;18:77-82. 
Dijk, G.M. van, Veenhof, C., Spreeuwenberg, P., Coene, N., Burger, B.J., Schaardenburg, D.J. van, Ende, C.H.M. van den, Lankhorst, G.J., Dekker, J. Prognosis of limitations in activities in osteoarthritis of the hip or knee: a 3-year cohort study. Archives of Physical Medicine and Rehabilitation: 2010, 91(1), 58-66

36. Stroop J, Hammes JG. Stroop Kleur-Woord test. In: Bouma A, Mulder J, Lindenboom J, editors. Neuropsychologische diagnostiek.

1996; Lisse: Swets \& Zeitlinger. p G1-12.

37. Angst F, Aeschlimann A, Stucki G. Smallest detectable and minimal clinically important differences of rehabilitation intervention with their implications for required sample sizes using WOMAC and SF-36 quality of life measurement instruments in patients with osteoarthritis of the lower extremities. Arthritis Rheum 2001;45: 384-91.

38. Tubach F, Ravaud P, Baron G, et al. Evaluation of clinically relevant changes in patient reported outcomes in knee and hip osteoarthritis: the minimal clinically important improvement. Ann Rheum Dis 2005;64:29-33.

39. Ayis S, Ebrahim S, Williams S, Juni P, Dieppe P. Determinants of reduced walking speed in people with musculoskeletal pain.

J Rheumatol 2007;34:1905-12.

40. Terwee C, van der Slikke R, van Lummel R, Benink R, Meijers W, de Vet H. Self reported physical functioning was more influenced by pain than performance-based physical functioning in knee osteoarthritis patients. J Clin Epidemiol 2006;59: 724-31.

41. Kadam UT, Croft PR. Clinical comorbidity in osteoarthritis: associations with physical function in older patients in family practice.

J Rheumatol 2007;34:1899-904.

42. Rijken M, van Kerkhof M, Dekker J, Schellevis FG. Comorbidity of chronic diseases: effects of disease pairs on physical and mental functioning. Qual Life Res 2005;14:45-55.

\section{Suppliers}

a. Biometrics BV, Transistorstraat 46-II, 1322 CG Almere, The Netherlands.

b. SPSS Inc, 233 S Wacker Dr, 11th FI, Chicago, IL 60606.

\section{TABLES, FIGURES, LISTS, APPENDIXES}

\section{[LIST 1]}

\section{List of Abbreviations}

$\begin{array}{ll}\text { BMI } & \text { body mass index } \\ \text { CIRS } & \text { Cumulative Illness Rating Scale } \\ \text { OA } & \text { osteoarthritis } \\ \text { ROM } & \text { range of motion } \\ \text { VAS } & \text { visual analog scale } \\ \text { WOMAC } & \text { Western Ontario and McMaster Universities } \\ & \text { Osteoarthritis Index }\end{array}$


Dijk, G.M. van, Veenhof, C., Spreeuwenberg, P., Coene, N., Burger, B.J., Schaardenburg, D.J. van, Ende, C.H.M. van den, Lankhorst, G.J., Dekker, J. Prognosis of limitations in activities in osteoarthritis of the hip or knee: a 3-year cohort study. Archives of Physical Medicine and Rehabilitation: 2010, 91(1), 58-66

\section{[TABLE 1]}

Table 1: Baseline Characteristics of the Study Population, Patients With Knee OA ( $n=174)$, and Patients With Hip OA $(n=123)$

\begin{tabular}{|c|c|c|}
\hline Characteristics & $\begin{array}{l}\text { Knee OA } \\
(n=174)\end{array}$ & $\begin{array}{l}\text { Hip OA } \\
(\mathrm{n}=123)\end{array}$ \\
\hline Age (y) (range, 50-83y) & $65.9 \pm 8.3$ & $66.3 \pm 8.9$ \\
\hline Sex, male & $46(26.4)$ & $36(29.3)$ \\
\hline Duration of complaints $(y)$ & $10.8 \pm 11.1$ & $7.7 \pm 9.3$ \\
\hline BMI $\left(\mathrm{kg} / \mathrm{m}^{2}\right)$ & $28.4 \pm 4.3$ & $26.8 \pm 3.7$ \\
\hline \multicolumn{3}{|l|}{ Obesity } \\
\hline $\mathrm{BMI}>30$ & $31(17.9)$ & $40(32.8)$ \\
\hline $25<\mathrm{BMI} \leq 30$ & $95(54.9)$ & $60(49.2)$ \\
\hline $\mathrm{BMI} \leq 25$ & $47(27.2)$ & $22(18.0)$ \\
\hline No other joint complaints & $20(11.6)$ & $14(11.5)$ \\
\hline Married & $106(60.9)$ & $89(72.4)$ \\
\hline \multicolumn{3}{|l|}{ Education } \\
\hline No or lower education ( $\leq 6 \mathrm{y})$ & $28(16.2)$ & $19(15.4)$ \\
\hline Medium education ( $\leq 12 \mathrm{y})$ & $121(69.9)$ & $84(68.3)$ \\
\hline Higher education (>12y) & $24(13.9)$ & $20(16.3)$ \\
\hline \multicolumn{3}{|l|}{ Radiologic evidence knee* } \\
\hline $\begin{array}{l}\text { Kellgren \& Lawrence } \\
\quad \text { grade } \geq 2\end{array}$ & $118(95.2)$ & $29(90.6)$ \\
\hline \multicolumn{3}{|l|}{ Radiologic evidence hip ${ }^{+}$} \\
\hline $\begin{array}{l}\text { Kellgren } \& \text { Lawrence } \\
\quad \text { grade } \geq 2\end{array}$ & $25(92.6)$ & $82(97.6)$ \\
\hline $\begin{array}{l}\text { WOMAC (physical functioning) } \\
\text { (range, } 0-100)\end{array}$ & $62.1 \pm 16.6$ & $61.9 \pm 16.4$ \\
\hline Timed walking test $(\mathrm{s})$ & $10.2 \pm 3.7$ & $10.0 \pm 2.7$ \\
\hline \multicolumn{3}{|l|}{ Muscle strength $(\mathrm{N})$} \\
\hline Hip abduction & $8.9 \pm 2.3$ & $9.2 \pm 2.3$ \\
\hline Knee extension & $7.6 \pm 2.3$ & $7.9 \pm 2.4$ \\
\hline \multicolumn{3}{|l|}{ ROM (deg) } \\
\hline Hip external rotation & $25.9 \pm 6.9$ & $24.1 \pm 6.9$ \\
\hline Hip internal rotation & $28.1 \pm 6.3$ & $26.5 \pm 6.2$ \\
\hline Hip flexion & $111.8 \pm 9.7$ & $109.9 \pm 10.0$ \\
\hline Knee extension & $-11.1 \pm 9.7$ & $-10.5 \pm 5.0$ \\
\hline Knee flexion & $129.0 \pm 9.5$ & $132.5 \pm 8.2$ \\
\hline Pain (VAS) $(\mathrm{cm})$ (range, 0-10) & $5.0 \pm 2.4$ & $4.6 \pm 2.5$ \\
\hline \multicolumn{3}{|l|}{ Comorbidity } \\
\hline $\begin{array}{l}\text { Morbidity count }(\mathrm{CIRS} \geq 2 \text { ) } \\
\quad \text { (range, } 0-12)\end{array}$ & $2.0(1.0 ; 4.0)$ & $3.0(1.0 ; 4.0)$ \\
\hline \multicolumn{3}{|l|}{ Cognitive functioning } \\
\hline CST20 (range, $0-20$ ) & $19.5(18.0 ; 20.0)$ & $19.5(19.0 ; 20.0)$ \\
\hline Cognitive decline on CST20 & $0(0)$ & $0(0)$ \\
\hline $\begin{array}{l}\text { Numbers forward: no. of } \\
\text { correct answers (range, } \\
\text { 0-21) }\end{array}$ & $12.2 \pm 2.9$ & $11.9 \pm 3.0$ \\
\hline $\begin{array}{l}\text { Numbers backward: no. of } \\
\text { correct answers (range, } \\
0-21 \text { ) }\end{array}$ & $8.5 \pm 3.0$ & $8.4 \pm 2.8$ \\
\hline Stroop interference score & $30.0 \pm 14.1$ & $32.0 \pm 17.5$ \\
\hline $\begin{array}{l}\text { Stroop no. of uncorrected } \\
\text { mistakes }\end{array}$ & $0.0(0.0 ; 1.0)$ & $0.0(0.0 ; 1.0)$ \\
\hline
\end{tabular}

NOTE. Values are mean \pm SD, $\mathrm{n}(\%)$, or median (25th percentile; 75 th percentile).

Abbreviation: CST20, 20-item cognitive screening test.

${ }^{*} \mathrm{n}=124$ (radiographs were available in only a subsample of the included patients).

${ }^{+} n=85$ (radiographs were available in only a subsample of the included patients). 
Dijk, G.M. van, Veenhof, C., Spreeuwenberg, P., Coene, N., Burger, B.J., Schaardenburg, D.J. van, Ende, C.H.M. van den, Lankhorst, G.J., Dekker, J. Prognosis of limitations in activities in osteoarthritis of the hip or knee: a

\section{[FIGURE 1]}

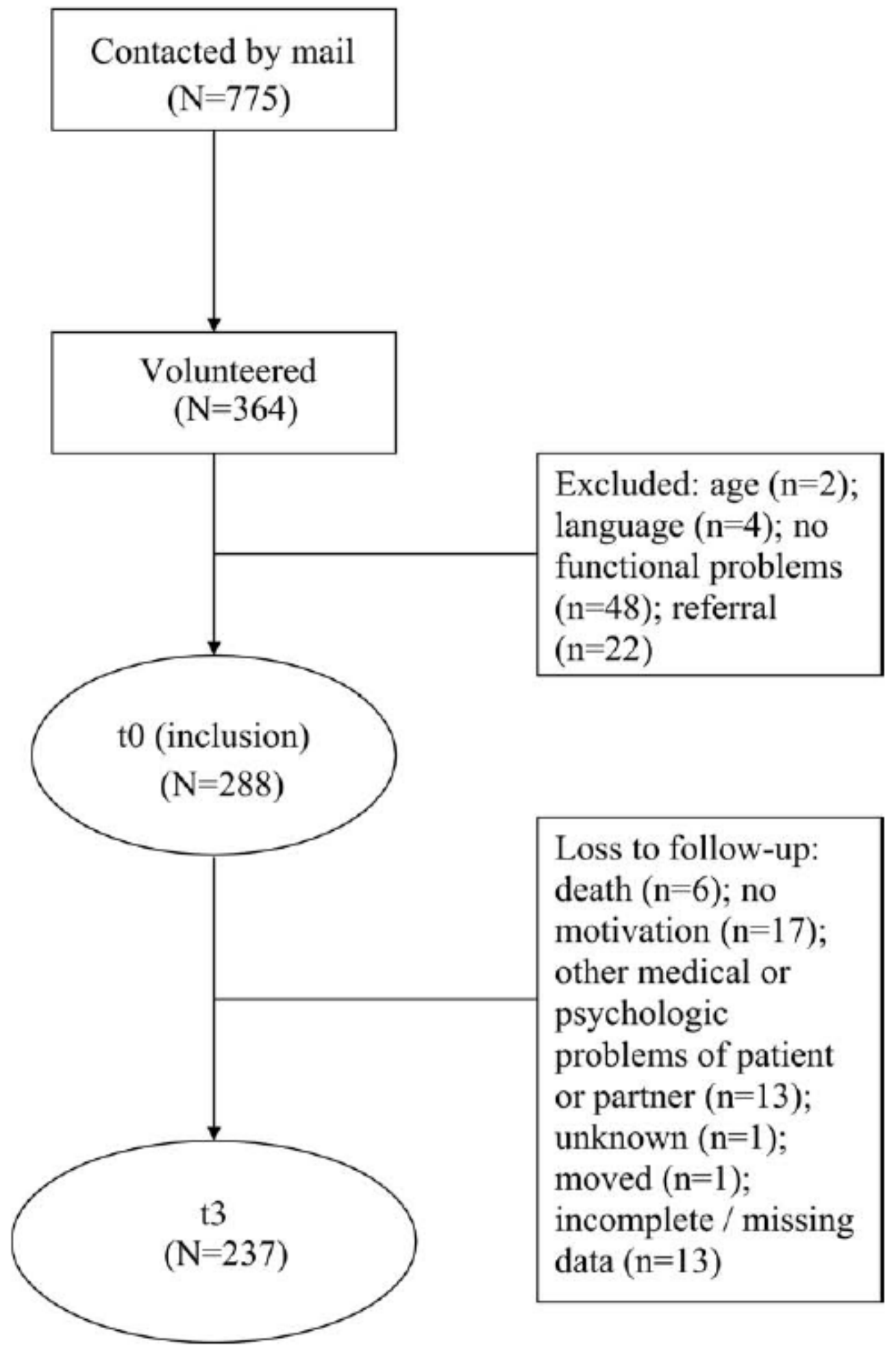

Fig 1. Flow chart of inclusion and follow-up. 
Dijk, G.M. van, Veenhof, C., Spreeuwenberg, P., Coene, N., Burger, B.J., Schaardenburg, D.J. van, Ende, C.H.M. van den, Lankhorst, G.J., Dekker, J. Prognosis of limitations in activities in osteoarthritis of the hip or knee: a 3-year cohort study. Archives of Physical Medicine and Rehabilitation: 2010, 91(1), 58-66

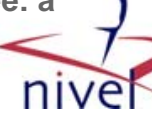

\section{[TABLE 2]}

Table 2: Course of Self-Reported and Performance-Based Limitations in Activities*

\begin{tabular}{|c|c|c|c|c|c|c|}
\hline Measures & $\begin{array}{c}\text { Location } \\
\text { of } O A\end{array}$ & $\begin{array}{l}\text { No. of } \\
\text { Patients }\end{array}$ & to & $\mathrm{t} 1$ & t2 & $\mathrm{t} 3$ \\
\hline \multicolumn{7}{|l|}{ WOMAC } \\
\hline & Knee & 173 & $62.1 \pm 16.6$ & $\begin{array}{c}64.2 \pm 17.7 \\
-1.9 \pm 14.7^{\S}\end{array}$ & $\begin{array}{r}66.9 \pm 18.1^{ \pm} \\
-4.5 \pm 17.5^{5}\end{array}$ & $\begin{array}{r}65.7 \pm 19.2^{\ddagger} \\
3.6 \pm 17.2^{5}\end{array}$ \\
\hline & Hip & 121 & $61.9 \pm 16.4$ & $\begin{array}{c}65.4 \pm 17.6 \\
-3.1 \pm 17.1^{5}\end{array}$ & $\begin{array}{c}69.6 \pm 18.3^{\ddagger} \\
-6.8 \pm 18.3^{\text {ई }}\end{array}$ & $\begin{array}{c}66.0 \pm 18.4^{\ddagger} \\
-4.1 \pm 16.7^{5}\end{array}$ \\
\hline \multicolumn{7}{|c|}{ Timed walking test (s) } \\
\hline & Knee & 134 & $9.9 \pm 3.6$ & $\begin{array}{l}9.6 \pm 2.5 \\
0.5 \pm 3.1^{\text {§ }}\end{array}$ & $\begin{array}{l}9.7 \pm 2.4 \\
0.2 \pm 3.2^{5}\end{array}$ & $\begin{array}{c}10.1 \pm 2.8 \\
-0.1 \pm 3.4^{5}\end{array}$ \\
\hline & Hip & 96 & $9.6 \pm 2.2$ & $\begin{array}{l}9.4 \pm 2.6 \\
0.4 \pm 2.0^{\text {s }}\end{array}$ & $\begin{array}{l}9.4 \pm 2.4 \\
0.3 \pm 2.1^{\S}\end{array}$ & $\begin{array}{l}9.6 \pm 2.3 \\
0.0 \pm 2.8^{5}\end{array}$ \\
\hline
\end{tabular}

NOTE. Values are mean \pm SD or as otherwise indicated.

Abbreviation: $t$, measurement.

${ }^{*}$ Means at $\mathrm{t} 0, \mathrm{t} 1, \mathrm{t} 2$, and $\mathrm{t} 3$ on WOMAC and timed walking test are presented. Means at $\mathrm{t} 1, \mathrm{t} 2$, and $\mathrm{t} 3$ were compared with $\mathrm{t} 0$ and statistically tested.

${ }^{\ddagger} P<.01$.

${ }^{5}$ Change score $\pm \mathrm{SD}$ : difference between $\mathrm{t} 1, \mathrm{t} 2, \mathrm{t} 3$ and $\mathrm{t} 0$. 
Dijk, G.M. van, Veenhof, C., Spreeuwenberg, P., Coene, N., Burger, B.J., Schaardenburg, D.J. van, Ende, C.H.M. van den, Lankhorst, G.J., Dekker, J. Prognosis of limitations in activities in osteoarthritis of the hip or knee: a

[TABLE 3]

Table 3: Factors Associated With the Course of Self-Reported Limitations in Activities (WOMAC): Results From the Univariate Analyses*

\begin{tabular}{lrr}
\hline \multicolumn{1}{c}{ Variables } & $\begin{array}{r}\text { Knee OA } \\
(\mathrm{n}=174)\end{array}$ & $\begin{array}{r}\text { Hip OA } \\
(\mathrm{n}=123)\end{array}$ \\
\hline WOMAC t0 & $.543^{\ddagger}$ & $.547^{\ddagger}$ \\
ROM & & \\
Hip external rotation: change from t0 to t1 & $.182^{\dagger}$ & $.227^{\ddagger}$ \\
Knee extension & -.043 & $.177^{\dagger}$ \\
Knee extension: change from t0 to t1 & -.009 & $-.199^{\dagger}$ \\
Pain & & \\
Pain (VAS): change from t0 to t1 & $-.214^{\ddagger}$ & $-.274^{\ddagger}$ \\
Comorbidity & & \\
Morbidity count (CIRS $\geq 2)$ & $-.213^{\ddagger}$ & $-.289^{\ddagger}$ \\
Presence of: & & \\
CIRS 1 (CIRS $\geq 2)$ & $-.124^{\S}$ & $-.275^{\ddagger}$ \\
CIRS 2 (CIRS $\geq 2)$ & $-.110^{5}$ & .120 \\
CIRS 6 (CIRS $\geq 2)$ & -.090 & $-.184^{\dagger}$ \\
CIRS 9 (CIRS $\geq 2)$ & $-.129^{\dagger}$ & -.106 \\
CIRS 13 (CIRS $\geq 2)$ & $-.110^{\S}$ & -.090 \\
Cognitive functioning & & \\
Numbers forward & .043 & $.218^{\ddagger}$ \\
Numbers backward & $.112^{\S}$ & $.181^{\dagger}$ \\
Stroop uncorrected mistakes & -.042 & $-.195^{\dagger}$ \\
Other factors & & \\
Age & .019 & $-.144^{\S}$ \\
\hline Ab & &
\end{tabular}

Abbreviation: $t$, measurement.

* Standardized $\beta$ values are presented.

${ }^{+} P<.05 ;{ }^{\ddagger} P<.01 ;{ }^{\text {s }} P<0.1$.

"For description of CIRS categories 1-13, see appendix 1 . 
Dijk, G.M. van, Veenhof, C., Spreeuwenberg, P., Coene, N., Burger, B.J., Schaardenburg, D.J. van, Ende, C.H.M. van den, Lankhorst, G.J., Dekker, J. Prognosis of limitations in activities in osteoarthritis of the hip or knee: a 3-year cohort study. Archives of Physical Medicine and Rehabilitation: 2010, 91(1), 58-66

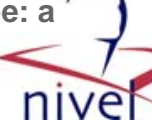

\section{[TABLE 4]}

Table 4: Factors Associated With the Course of Self-Reported Limitations in Activities (WOMAC): Results From the Multivariate Analyses*

\begin{tabular}{|c|c|c|c|c|c|c|}
\hline \multirow[b]{2}{*}{ Variables } & \multicolumn{6}{|c|}{ Prognostic Factors Entered Per Block } \\
\hline & $\begin{array}{l}\text { Score for } \\
\text { WOMAC at t0 }\end{array}$ & $\begin{array}{c}\text { ROM and } \\
\text { Muscle Strength" }\end{array}$ & Pain & Comorbidity $\#$ & $\begin{array}{l}\text { Cognitive } \\
\text { Functioning }\end{array}$ & Other" \\
\hline Knee OA & & & & & ॠ & ฯ \\
\hline Explained variance & $R^{2}=.286$ & $R^{2}=.314$ & $R^{2}=.347$ & $R^{2}=.373$ & & \\
\hline \multicolumn{7}{|l|}{ Significant prognostic factors in the model: } \\
\hline WOMAC t0 & $.539^{\ddagger}$ & $.528^{ \pm}$ & $.582^{\ddagger}$ & $.539^{\ddagger}$ & & \\
\hline Change in ROM hip external rotation from to to $\mathrm{t} 1$ & & $.182^{+}$ & $.135^{5}$ & $.120^{5}$ & & \\
\hline Change in pain from to to $t 1$ & & & $-.204^{ \pm}$ & $-.177^{+}$ & & \\
\hline Morbidity count $(\mathrm{CIRS} \geq 2)$ & & & & $-.180^{+}$ & & \\
\hline Hip OA & & & & & & ฯ \\
\hline Explained variance & $R^{2}=.324$ & $R^{2}=.374$ & $R^{2}=.444$ & $R^{2}=.476$ & $R^{2}=.504$ & \\
\hline \multicolumn{7}{|l|}{ Significant prognostic factors in the model: } \\
\hline WOMAC t0 & $.575^{ \pm}$ & $.575^{ \pm}$ & $.649^{ \pm}$ & $.566^{\ddagger}$ & $.552^{\ddagger}$ & \\
\hline Change in ROM hip external rotation from to to $\mathrm{t} 1$ & & $.215^{ \pm}$ & $.184^{+}$ & $.200^{\ddagger}$ & $.201^{ \pm}$ & \\
\hline Change in ROM knee extension from to to $t 1$ & & $-.169^{+}$ & $-.159^{\dagger}$ & $-.169^{+}$ & $.144^{5}$ & \\
\hline Change in pain from to to $t 1$ & & & $-.241^{\ddagger}$ & $-.164^{5}$ & $-.134^{\|}$ & \\
\hline Morbidity count $(\mathrm{CIRS} \geq 2)$ & & & & $-.213^{+}$ & $-.220^{\ddagger}$ & \\
\hline Numbers forward & & & & & $.181^{\dagger}$ & \\
\hline
\end{tabular}

NOTE. Variables with $P<.05$ are entered into the analyses. Variables with $P>0.2$ were excluded from the model.

Abbreviations: $R^{2}$, explained variance; t, measurement.

* Standardized $\beta$ values are presented.

${ }^{+} P<.05 ;{ }^{\ddagger} P<.01 ;{ }^{\S} P<0.1 ;{ }^{\| l} P<0.2$.

"Factors were not included in the model and did not contribute to the explained variance.

"Prognostic factors were added to the variables presented in the previous column. 
Dijk, G.M. van, Veenhof, C., Spreeuwenberg, P., Coene, N., Burger, B.J., Schaardenburg, D.J. van, Ende, C.H.M. van den, Lankhorst, G.J., Dekker, J. Prognosis of limitations in activities in osteoarthritis of the hip or knee: a

[TABLE 5]

Table 5: Factors Associated With the Course of Performance-Based Limitations in Activities (Timed Walking Test): Results From the Univariate Analyses*

\begin{tabular}{|c|c|c|}
\hline Variables & $\begin{array}{c}\text { Knee OA } \\
(n=113)\end{array}$ & $\begin{array}{l}\text { Hip OA } \\
(\mathrm{n}=83)\end{array}$ \\
\hline Timed walking test t0 & $.469^{\ddagger}$ & $.520^{ \pm}$ \\
\hline \multicolumn{3}{|l|}{ ROM } \\
\hline Hip flexion & .061 & $.220^{+}$ \\
\hline Hip flexion: change from to to $t 1$ & $-.149^{\S}$ & $-.175^{\S}$ \\
\hline \multicolumn{3}{|l|}{ Muscle strength } \\
\hline Knee extension: change from to to $\mathrm{t} 1$ & $-.145^{\S}$ & .012 \\
\hline Hip abduction & $-.154^{\S}$ & -.115 \\
\hline Hip abduction: change from to to $\mathrm{t} 1$ & $-.280^{\ddagger}$ & $-.193^{5}$ \\
\hline \multicolumn{3}{|l|}{ Comorbidity } \\
\hline Morbidity count (CIRS $\geq 2$ ) & $.218^{\ddagger}$ & $.304^{\ddagger}$ \\
\hline \multicolumn{3}{|l|}{ Presence of: } \\
\hline CIRS $1(\mathrm{CIRS} \geq 2)^{\|}$ & .075 & $.218^{\dagger}$ \\
\hline CIRS $3(\mathrm{CIRS} \geq 2)$ & $.208^{\ddagger}$ & -.005 \\
\hline CIRS $4($ CIRS $\geq 2)$ & .149 & $.247^{ \pm}$ \\
\hline CIRS 5 (CIRS $\geq 2)$ & .037 & $.208^{+}$ \\
\hline CIRS 9 (CIRS $\geq 2)$ & $.136^{5}$ & .117 \\
\hline CIRS $12(\mathrm{CIRS} \geq 2)$ & .060 & $.188^{\dagger}$ \\
\hline CIRS $13(\mathrm{CIRS} \geq 2)$ & $.157^{+}$ & $.201^{+}$ \\
\hline \multicolumn{3}{|l|}{ Cognitive functioning } \\
\hline Stroop interference score & -.083 & $.162^{5}$ \\
\hline \multicolumn{3}{|l|}{ Other factors } \\
\hline Age & .059 & $.360^{\ddagger}$ \\
\hline Surgery before inclusion & $-.134^{5}$ & -.108 \\
\hline $\mathrm{BMI}$ & $.145^{5}$ & -.078 \\
\hline Obesity (BMI >30) & .017 & -.064 \\
\hline
\end{tabular}

Abbreviation: $t$, measurement.

* Standardized $\beta$ values are presented.

${ }^{+} P<.05 ;{ }^{\ddagger} P<.01 ;{ }^{\S} P<0.1$.

"For description of CIRS categories 1-13, see appendix 1. 
Dijk, G.M. van, Veenhof, C., Spreeuwenberg, P., Coene, N., Burger, B.J., Schaardenburg, D.J. van, Ende, C.H.M. van den, Lankhorst, G.J., Dekker, J. Prognosis of limitations in activities in osteoarthritis of the hip or knee: a

3-year cohort study. Archives of Physical Medicine and Rehabilitation: 2010, 91(1), 58-66

\section{[TABLE 6]}

Table 6: Factors Associated With the Course Of Performance-Based Limitations in Activities (Timed Walking Test): Results From the Multivariate Analyses*

\begin{tabular}{|c|c|c|c|c|c|c|}
\hline \multirow[b]{2}{*}{ Variables } & \multicolumn{6}{|c|}{ Prognostic Factors Entered Per Block } \\
\hline & $\begin{array}{l}\text { Score for Timed } \\
\text { Walking Test at to }\end{array}$ & $\begin{array}{c}\text { ROM and } \\
\text { Muscle Strength" }\end{array}$ & Pain $\#$ & Comorbidity ${ }^{\#}$ & $\begin{array}{l}\text { Cognitive } \\
\text { Functioning }\end{array}$ & Other" \\
\hline Knee OA & & & $\|$ & & $\|$ & $\|$ \\
\hline Explained variance & $R^{2}=.285$ & $R^{2}=.358$ & & $R^{2}=.391$ & & \\
\hline \multicolumn{7}{|l|}{ Significant prognostic factors in the model: } \\
\hline Timed walking test to & $.541^{\ddagger}$ & $.541^{ \pm}$ & & $.512^{\ddagger}$ & & \\
\hline Change in muscle strength hip abduction from to to $\mathrm{t} 1$ & & $-.280^{\ddagger}$ & & $-.272^{\ddagger}$ & & \\
\hline Morbidity count (CIRS $\geq 2$ ) & & & & $.199^{+}$ & & \\
\hline Hip OA & & & $\|$ & & $\|$ & \\
\hline Explained variance & $R^{2}=.232$ & $R^{2}=.262$ & & $R^{2}=.331$ & & $R^{2}=.450$ \\
\hline \multicolumn{7}{|l|}{ Significant prognostic factors in the model: } \\
\hline Timed walking test to & $.490^{ \pm}$ & $.592^{ \pm}$ & & $.540^{\ddagger}$ & & $.490^{ \pm}$ \\
\hline ROM hip flexion & & $.220^{+}$ & & $.191^{5}$ & & $.182^{+}$ \\
\hline Morbidity count (CIRS $\geq 2$ ) & & & & $.278^{\ddagger}$ & & $.232^{ \pm}$ \\
\hline Age & & & & & & $.355^{ \pm}$ \\
\hline
\end{tabular}

NOTE. Variables with $P<0.5$ are entered into the analyses. Variables with $P>0.2$ were excluded from the model. Abbreviations: $R^{2}$, explained variance; t, measurement.

* Standardized $\beta$ values are presented.

${ }^{+} P<.05 ;{ }^{\ddagger} P<.01 ;{ }^{5} P<0.1$.

"Factors were not included in the model and did not contribute to the explained variance.

"Prognostic factors were added to the variables presented in the previous column.

\section{[TABLE 7]}

\section{Table 7: Prognostic Factors for Worsening of Self-Reported} Limitations in Activities

\begin{tabular}{cc}
\hline $\begin{array}{c}\text { Patient } \\
\text { Groups }\end{array}$ & \multicolumn{1}{c}{$\begin{array}{c}\text { Factors Associated With Worsening of } \\
\text { Self-Reported Limitations in Activities* }\end{array}$} \\
\hline Knee OA & - Reduced ROM hip external rotation at 1-year \\
& follow-up \\
- Increased pain at 1-year follow-up & - Higher morbidity count \\
- Reduced ROM hip external rotation and knee & extension at 1-year follow-up \\
- Increased pain at 1-year follow-up & - Higher morbidity count or the presence of \\
& moderate to severe cardiac disease \\
& - Poorer cognitive functioning
\end{tabular}

*All prognostic factors are included that were found to be significant in the multivariate regression analyses. 
Dijk, G.M. van, Veenhof, C., Spreeuwenberg, P., Coene, N., Burger, B.J., Schaardenburg, D.J. van, Ende, C.H.M. van den, Lankhorst, G.J., Dekker, J. Prognosis of limitations in activities in osteoarthritis of the hip or knee: a

\section{[TABLE 8]}

\section{Table 8: Prognostic Factors for Worsening of Performance-Based Limitations in Activities}

\begin{tabular}{|c|c|}
\hline $\begin{array}{l}\text { Patient } \\
\text { Groups }\end{array}$ & $\begin{array}{l}\text { Factors Associated With Worsening of Performance-Based } \\
\text { Limitations in Activities* }\end{array}$ \\
\hline Knee OA & $\begin{array}{l}\text { - Decreased muscle strength hip abduction at 1-year } \\
\text { follow-up } \\
\text { - Higher morbidity count }\end{array}$ \\
\hline Hip OA & $\begin{array}{l}\text { - Higher ROM hip flexion at baseline } \\
\text { - Higher morbidity count or the presence of } \\
\text { moderate to severe cardiac and ear-eye-nose- } \\
\text { throat-larynx disease } \\
\text { - Older age }\end{array}$ \\
\hline
\end{tabular}

*All prognostic factors are included that were found to be significant in the multivariate regression analyses.

\section{[APPENDIX 1]}

APPENDIX 1: THE CUMULATIVE ILLNESS RATING SCALE

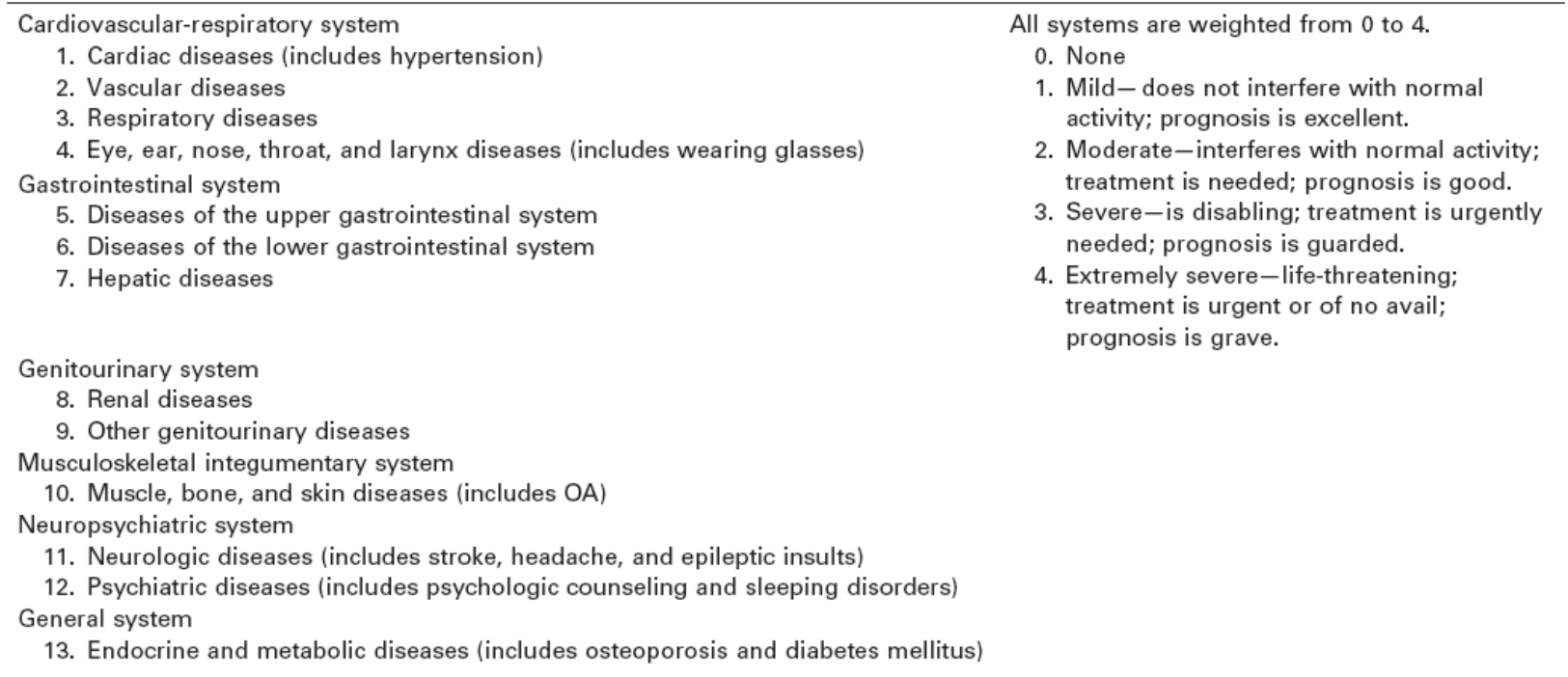

